Perspectiva Geográfica

ISSN 0123-3769 (Impreso) - 2500-8684 (En línea)

Vol. 21 No. 1 de 2016

Enero - Junio pp. 151-178

\title{
Análisis geo histórico del proceso de urbanización en América del Sur: de la ciudad indoamericana a la ciudad neoliberal
}

Geo Historical Analysis of the Urbanization Process in South America: From the Pre Columbian to the Modern Neoliberal Period

Jorge Andrés Rivera Pabón ${ }^{1}$

Para citar este artículo utilice el nombre completo así:

Rivera, J. (2016). Análisis geo-histórico del proceso de urbanización en América del Sur: de la ciudad indoamericana a la ciudad neoliberal. Perspectiva Geográfica, 21(1), 151-178.

\section{Resumen}

Este artículo examina, desde una mirada diacrónica, estructural y endógena, el proceso de urbanización en América del Sur, teniendo como principales elementos de análisis la estructura del poblamiento y las dinámicas urbanas acaecidas desde la fase de desarrollo precolombino hasta el periodo actual, de orden neoliberal; para ello, se desarrolla una metodología cualitativa que utiliza como técnica investigativa la revisión documental de información histórica, geopolítica y cartográfica, y, como fuentes primarias, el trabajo de campo y la fotografía.

Palabras clave: América del sur, geo-historia, procesos de poblamiento, urbanización.

1 Doctor en Geografía, Planificación Territorial y Gestión Ambiental, Universidad de Barcelona. Docente del Departamento de Historia y Geografía, Facultad de Ciencias Jurídicas y Sociales, Universidad de Caldas, Colombia. Miembro del Grupo de Investigación Territorialidades. jorgeandres.rivera@ucaldas.edu.co; http://riverapabon.blogspot.com.co/ 


\section{Abstract}

This paper examines from a diachronic, structural and endogenous view the South American urbanization process, taking as main analytic elements the settlements' structure and the urban dynamics, occurred from the preColumbian development stage, to the contemporary period, the neoliberal order. For that purpose, a qualitative methodology is developed that uses the historical, geopolitical and cartographic documental information review as research techniques, and includes fieldwork and photography as primary sources.

Key Words: South America, geo-history, human settlement processes, urbanization. 
Introducción

A través del presente análisis geo-histórico se intenta identificar los factores estructurales que dan singularidad y atributos comunes a la urbanización en Suramérica, desde sus albores, en la época precolombina, pasando por su reconfiguración en el marco de la dominación colonial, y ulteriormente por las diversas fases de instauración del capitalismo, concluyendo en su último acápite de globalización neoliberal; es decir, a través del estudio diacrónico de las dinámicas endógenas y de las interdependencias establecidas entre la región y los cambios en el orden económico mundial. Para este fin, se consideran como fundamentos teóricos el enfoque historicista de la geografía cultural $^{2}$ y el materialismo históri-

2 Una de las bases interpretativas del artículo es el estudio histórico de los aspectos socio-espaciales que dan singularidad a los procesos de urbanización en América del sur. Para tal efecto, se contempla la tendencia historicista de la escuela de geografía cultural de Berkeley, la cual dejó una influencia decisiva en la América hispánica-tropical, verbigracia, el aporte intelectual de James Parsons, quien estudió en su obra sobre la colonización antioqueña en el occidente colombiano, el desarrollo económico y urbano de Medellín a partir del paso de la actividad artesanal a las grandes compañías de textiles, metalúrgicas, de cementos y bebidas, entre otras. En definitiva, como lo hace notar Horacio Capel (2002, p. 30), desde la tradición de la geografía cultural se generó una serie de estudios dedicados a los paisajes culturales, al igual que "a la evolución histórica de la ciudad y las etapas de la formación del plano urbano, con las principales co-geográfico de la geografía radical $^{3}$, siendo estos complementados por el acervo teórico de otras ciencias sociales, la arquitectura y el urbanismo ${ }^{4}$. De esta forma, el análisis se inscribe y gravita en la línea argumentativa de la geografía histórica, al auscultar la influencia de las formas espaciales "heredadas" en las nuevas producciones del espacio.

fases de crecimiento". De manera complementaria, se destacan los argumentos planteados por uno de los autores emblemáticos de la Geografía Histórica a nivel continental, como es Pedro Cunill Grau. Precisamente, este autor ha abordado el estudio de los tipos de poblamiento, las redes urbanas y el hábitat subintegrado de las ciudades latinoamericanas (citado con base en: Hiernaux, D; Lindón, A. 2006, p. 107).

3 A través del análisis dialéctico del materialismo histórico-geográfico, se indaga en la evolución de los procesos de poblamiento y urbanización en América del Sur en relación con las fases del desarrollo de la economía mundo: precolonial, colonial, nacionalrepublicano y de globalización neoliberal. Igualmente, se incorpora como factor clave para comprender la lógica de funcionamiento del proceso de urbanización, el papel de la acumulación capitalista (citado con base en: Santos P, J. M. 1992, p. 10). En este orden de ideas, se examina el rol que cumplen los agentes sociales en la dinámica inmobiliaria y el crecimiento urbano, la segregación residencial, etc. (citado con base en: Lois, R.C. 2012, p. 28).

4 En el estudio urbano para el subcontinente, se valora la influencia que han tenido desde la década de los setenta las orientaciones críticas de arquitectos, urbanistas, sociólogos y economistas como Roberto Segre, Jorge Enrique Hardoy, Nora Clichevsky y José Luis Coraggio, en Argentina; en Ecuador, Fernando Carrión; en Colombia, Orlando Sáenz, Fabio Velázquez y Jacques Aprile-Gniset, entre otros. En Brasil, Chile y España, respectivamente, Fernando Henrique Cardoso, Enzo Faletto, Manuel Castells y Jordi Borja, entre otros. 
En suma, el objetivo de este artículo es presentar un análisis multitemporal del proceso de urbanización en Suramérica, que permita avanzar en la comprensión crítica de su evolución, tal como se esboza de manera detallada a continuación.

\section{La ciudad indoamericana}

La existencia del fenómeno urbano en el continente americano, contrario a lo que se piensa usualmente, es un proceso de larga duración, que encuentra sus raíces más profundas y antecedentes iniciales en las ciudades construidas hace 2000 años, en una serie de regiones densamente pobladas y con una tradición agrícola propia de los denominados pueblos testimonio ${ }^{5} \mathrm{de}$ las sociedades imperiales americanas $^{6}$. Justamente, tal como lo indica el arquitecto y especialista en las ciudades precolombinas, Jorge Enrique Hardoy (2009, p. 35), “el proceso urbanístico en América no nació con la conquista. Es un pro-

5 Los pueblos testimonio son los sobrevivientes de las altas civilizaciones autónomas que sufrieron el impacto de la expansión europea, son el producto de la acción traumatizante de aquella expansión. Entre estos se cuentan los localizados en el Altiplano Andino (Bolivia, Perú, Ecuador). Citado por: Ribeiro D. En: Segre, R. 1996, p. 13, 14.

6 Citado con base en Hardoy, J. E. En: Segre R. 1996, p. 45. ceso que se desarrolla desde hace más de veinte siglos y en el que actualmente participan los descendientes de los centros ceremoniales".

De igual modo, los geógrafos María Asunción Martín Lou y Eduardo Múscar (1992, p. 86) esbozan, con relación al modelo de ocupación precolombino en América del Sur, que debido a la extensión del subcontinente, este estaba habitado por pueblos de características diferentes. En general, se establecen tres grandes áreas que reflejan el grado de desarrollo social de los grupos humanos que las ocupaban, cuya organización será un aspecto decisivo para el establecimiento del modelo colonial subsiguiente (Figura 1).

Así, en la estructura de poblamiento de los pueblos originarios se distinguió el incaico, que se extendía desde la cordillera de los Andes hasta la fachada pacífica. Por el contrario, en el resto de la región, a pesar de la amplia distribución de comunidades indígenas, no se presentó un modelo de dominación espacial, entre otras razones por el nivel primario de organización que las caracterizaba. Ahora bien, para el área nuclear centro andi- 
na sobresale como característica fundamental las localizaciones en altura, como es el caso de Machu Pichu. Aparte de esta condición, el territorio incaico funcionaba de acuerdo con el esquema centro-periferia, que generaba mayor pro-

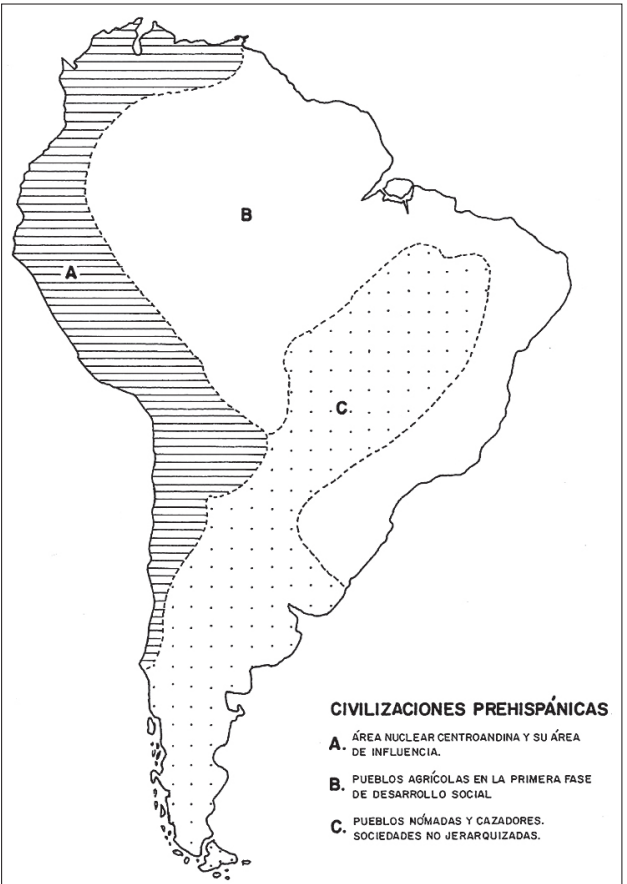

vecho para el centro, en este caso Cuzco, capital del imperio. Este modelo de ocupación espacial centrípeto se articuló a través del sistema de caminos y conexiones entre los poblados precolombinos.

Figura 1. Espacialidad de las civilizaciones prehispánicas, red de caminos y modelo centrípeto de dominación espacial.

Fuente: Martín y Múscar (1992, pp. 67, 83, 89).

Lo enunciado indica que en el marco del desarrollo autárquico de los grupos indígenas en Suramérica se produjeron unas formas de organización social y territorial que tuvieron como corolario espacial la preponderancia del poblamien-

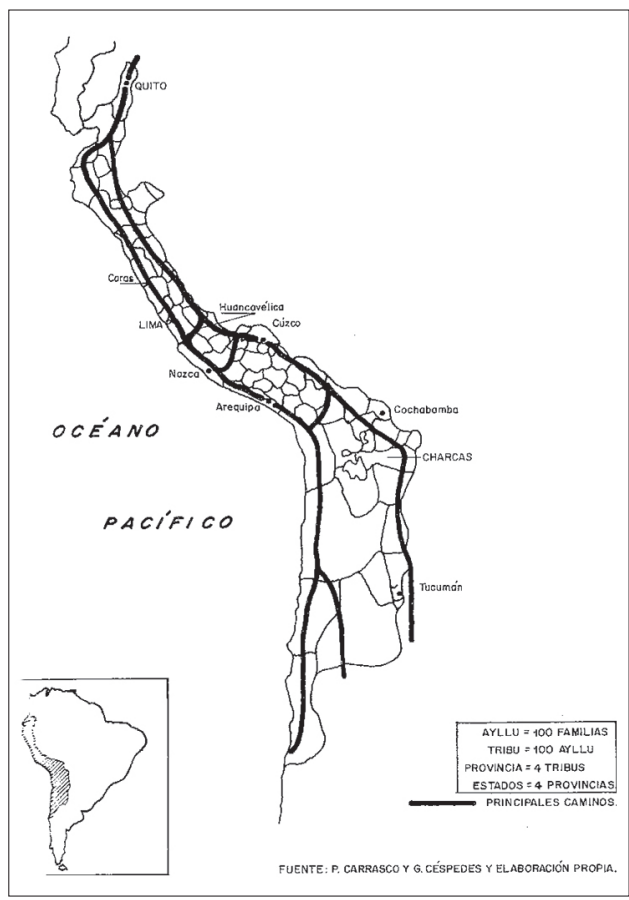

to interno, al tener sus centros de gobierno en zonas del interior, aunque también se constituyeron asentamientos costeros de máxima importancia, por ejemplo, Chan Chan en el Perú. 
Tabla 1. Suramérica. Patrones de asentamientos humanos y morfología urbana en el periodo precolombino

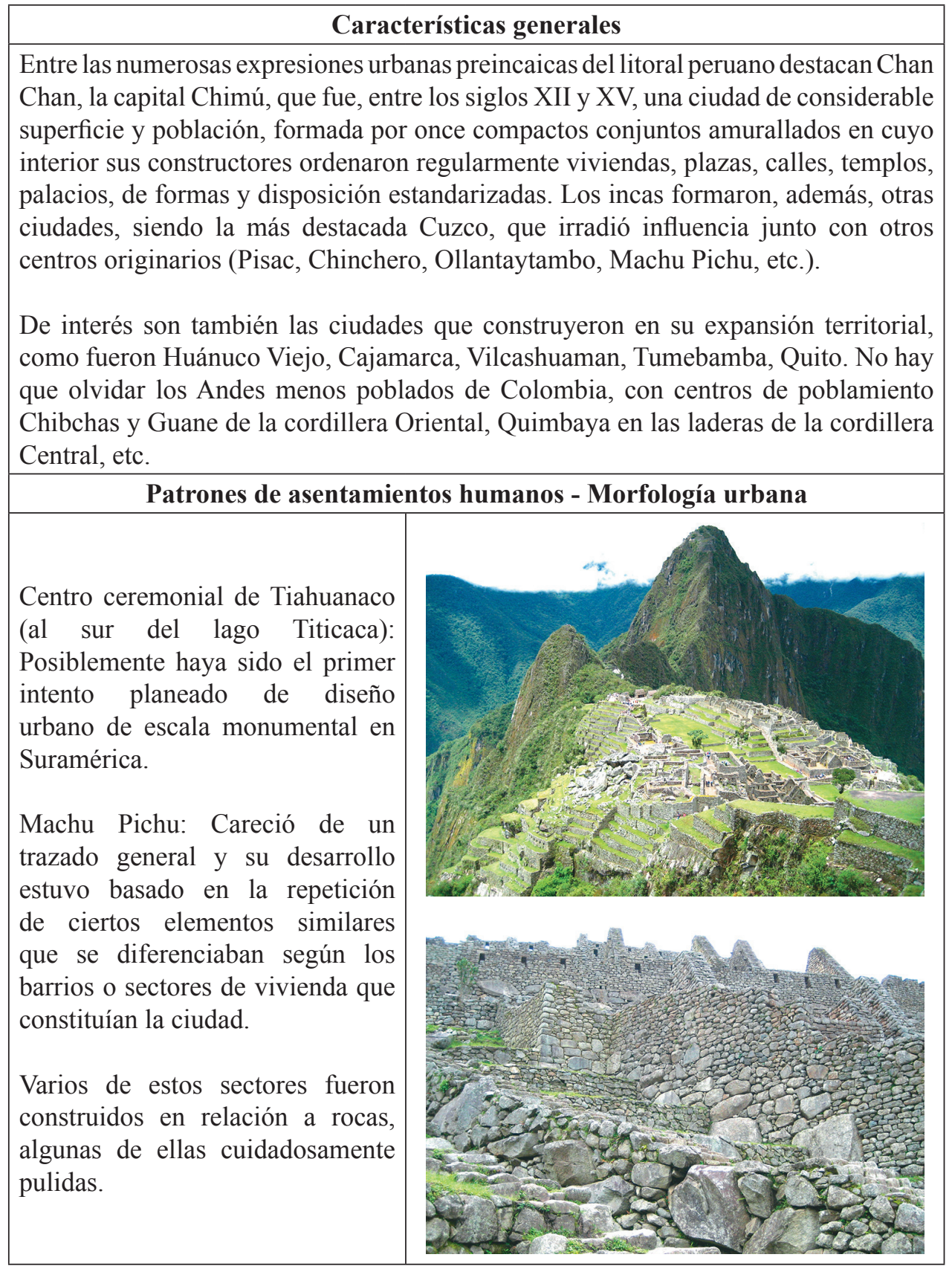

Fuente: Elaboración propia con base en Hardoy. En: Segre (1996, p. 46 y 47). Hardoy (2009, p. 419). Martín y Múscar (1992, p. 88). Cunill (1981, p. 212). Fotos: Jorge Andrés Rivera. 
En consecuencia, producto de una larga tradición de manejo, uso y apropiación del territorio por las comunidades indígenas en América del sur, se configuró una distribución espacial del poblamiento, en especial en el área centro-andina, que se constituye en la estructura originaria y columna vertebral del sistema actual de ciudades, toda vez que, como lo enuncia Hardoy: "los españoles emplazaron muchas de sus primeras fundaciones sobre las ciudades indígenas y los territorios más densamente poblados que acababan de conquistar" (2009, p. 14).

A continuación, con el propósito de poner en evidencia tanto la superposición del sistema urbano colonial sobre el territorio ancestral indígena y sus asentamientos humanos, como la nueva constitución de una amplia red de poblados de carácter litoral, se presentan las especificidades de la ciudad ibérica en Suramérica.

\section{La ciudad suramericana en la época de la conquista y colonia ibérica}

En Suramérica se identifica, desde la fase de penetración europea en el territorio indoamericano, la yu- xtaposición entre la estructura de poblamiento ancestral indígena y el sistema de ocupación espacial ibérico. En este sentido, una explicación de enorme capacidad aclaratoria sobre esta transposición es la realizada por el geógrafo Pedro Cunill Grau, en su texto La América Andina:

La época de conquista y colonización española dejó un esquema de distribución geográfica de la población de estas naciones, bastante parecido al poblamiento indígena a finales del siglo XV. Por ello, las mayores concentraciones de población se encuentran superpuestas a las antiguas concentraciones de población indígena: cordillera del litoral venezolano, Andes colombo-ecuatorianos, Sierra y Altiplano peruano-boliviano, Depresión Central chilena. A la vez los españoles fomentaron el poblamiento vertical y periférico en el litoral, buscando una mejor localización de sus puertos para asegurar el vínculo con la metrópoli (1981, p. 92).

Ciertamente, tal como se expone para el área andina, las formas de organización territorial de las culturas precolombinas cambiaron 
después del momento de contacto o "impacto" de la expansión europea desde finales del siglo XV. Por eso, tras la imposición del paradigma civilizatorio ibérico se generó, en primer lugar, la destrucción de los espacios urbanos indígenas precedentes, sobre los cuales se erigió la nueva ciudad colonial de altura $^{7}$, y, enseguida, se instauró un modelo de ocupación predominantemente costero, revelado en la conformación de una serie de ciudades portuarias para extraer a través de ellas la riqueza de los territorios dominados.

Esta condición de poblamiento litoral también se dio en Brasil, con la fundación de los puertos de Olinda, Porto Seguro, Espíritu Santo, Iguaracu, Santa Cruz Calabria, Ilheus y San Vicente. Para esta empresa de instauración colonial, la corona Lusitana recurrió al sistema de capitanías, otorgando enormes extensiones a capitales privados y órdenes religiosas. Así, los donatarios se dedicaron a la plantación azucarera, gestando y consolidando con el tiempo ciudades con gran dinamismo, como Salvador de Bahía, Recife, Pernambuco y Río de Janeiro. A continuación, se describe la especialización funcional del sistema de ciudades de suramérica en la fase colonial.

Tabla 2. Funciones urbanas y características del sistema de asentamientos en el periodo colonial

\section{Funciones urbanas}

Ciudades gestoras de exploraciones y nuevas fundaciones

\section{Observaciones generales}

Se presentan pruebas escritas en los relatos de cronistas de viajes, como Ruy Díaz de Guzmán, sobre el papel que cumplió Asunción (1537) como ciudad gestora de avanzadas colonizadoras y de nuevas fundaciones; igualmente, Martín Alfonso de Souza escribió acerca del rol de San Vicente y de Río de Janeiro, en 1532, en la conquista de nuevos territorios en Brasil.

$7 \quad$ Algunos ejemplos de "ciudades coloniales de altura", superpuestas sobre un espacio prehispánico son: Pasto (2594 m) y Bogotá (2630 m), en Colombia; Riobamba (2754 m), Latacunga (2771 m) y Quito (2818 m), en Ecuador; Huaraz (3091 m), Huancayo (3271 m), Cuzco (3399 m), Jauja (3410 m), Juliaca (3823 m), Cerro de Pasco (4338 m), en Perú, y La Paz (3632 m), Oruro (3703 m) y Potosí (4040 m), en Bolivia. 
Funciones urbanas

Ciudades portuarias y comerciales
Centros agrícolas, ganaderos y mineros: Ciudades residencia de grandes propietarios

\section{Observaciones generales}

Estas ciudades "comenzaron como puerto de enlace y terminales de las grandes rutas oceánicas”. Los principales puertos como El Callao, Buenos Aires, Río de Janeiro y Bahía, se constituyeron en centros comerciales y llegaron a convertirse en grandes ciudades. Por ejemplo, entre 1638 y 1642, Río de Janeiro y la Bahía de Guanabara establecieron anualmente hacia Portugal un promedio de 20 a 25 carabelas cargadas de azúcar. Por otra parte, El Callao fue punto clave para el transporte de la plata por el Pacífico, y las ciudades con función comercial en Argentina se correspondían con las instaladas en el interior como apoyo de las rutas terrestres, situación de La Rioja y Mendoza, o las que jalonaron el camino desde el Alto Perú hasta el río de la Plata, como Salta, Tucumán, Santiago del Estero y Córdoba, al igual que la consolidación posterior de Rosario como gran puerto fluvial interior.

Las ciudades que fungían como epicentros de regiones especializadas en la producción agropecuaria estuvieron amparadas en el modelo colonial de explotación económica del espacio rural, como las "chacras". Las plantaciones de azúcar, cacao o tabaco se localizaron en los terrenos bajos de las costas atlánticas de Brasil y Venezuela (Pernambuco, Olinda, Coro), y pacíficas de Ecuador (Guayaquil). Por el contrario, muchas ciudades andinas deben su origen y prosperidad a la explotación de riquezas mineras, ejemplo de ello son Huancavelica, Oruro, Potosí y cientos de pequeños centros urbanos que servían a la minería de la plata, el oro y el cobre.

A partir de la necesidad de tejer redes en medio de la Poblados de enlace y centros de tránsito compleja orografía andina para conectar las ciudades del litoral con las capitales de altura se forjó un rosario de ciudades que jalonaban rutas interiores. Como ejemplo destaca la que surgió en los valles y altiplanos del Reino de Nueva Granada, como núcleos de interrelación entre el Caribe y el Pacífico. Bogotá incentivó, por ejemplo, el surgimiento de muchos de estos núcleos; igual rol cumplió Quito, desde donde partieron estímulos, que explican fundaciones de varias ciudades del suroeste colombiano como Pasto, Popayán y Cali. 
Pueblos de indígenas

Los sistemas tradiciones de cultivos obligaban la dispersión de los indígenas, por lo que las nuevas instituciones coloniales exigieron la concentración de ellos en las cercanías de ciudades y villas: "es necesario que los indios se repartan en pueblos que vivan juntamente y que alli tenga cada uno su casa habitada con su mujer e hijos... La población indígena debía colaborar en las tareas productivas de los españoles bajo un trato servil, motivada, además, por compromisos espirituales". Los pueblos de indios tuvieron gran desarrollo en las regiones con alta densidad de población aborigen; en este sentido, las regiones andinas, el noroeste argentino y la región guaranítica fueron las que más testimonio han dado de esta manifestación.

Fuente: Elaboración propia a partir de Abreu (2013), Fridman (s,f.), Hardoy. En: Segre (1996, pp. 37-39). Martín, Múscar (1992, pp. 111-132). Cunill (1981, pp. 224, 225).
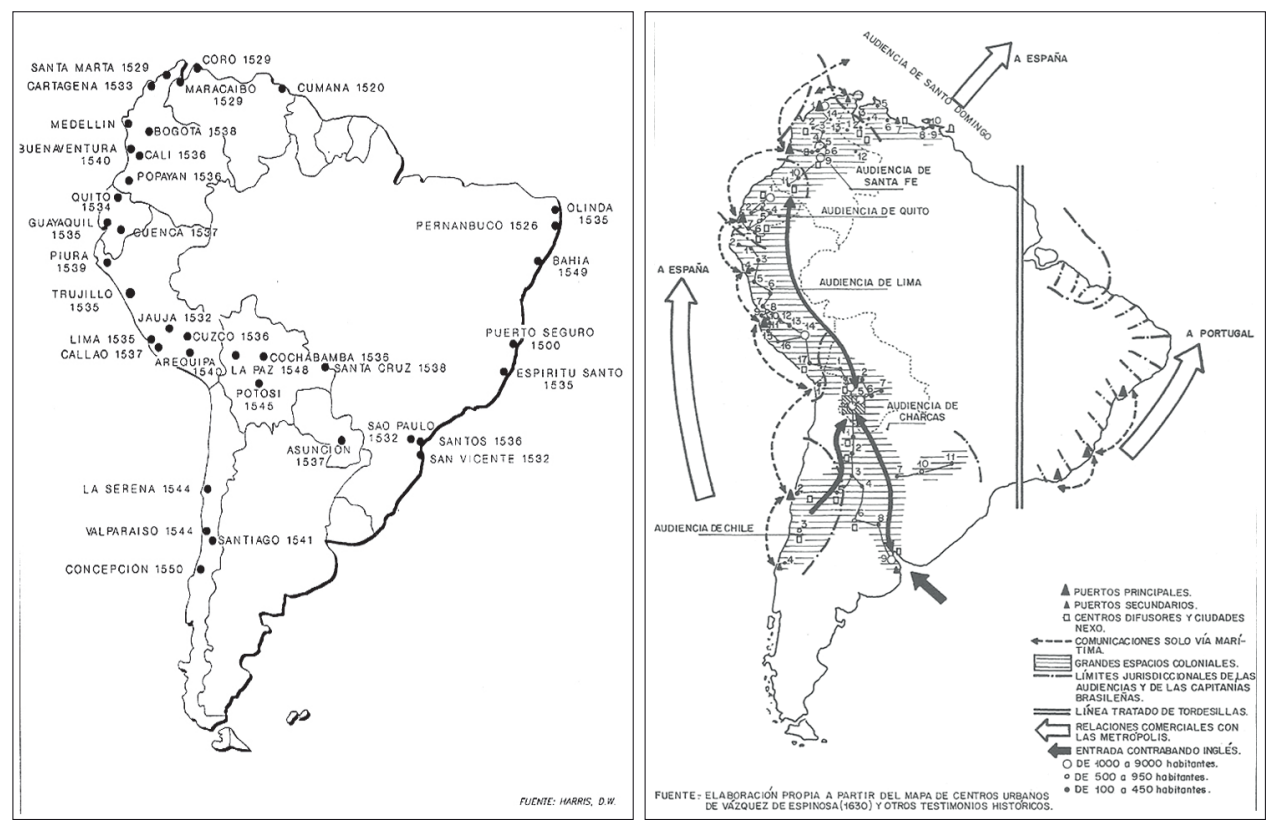

Figura 2. Principales ciudades fundadas en la primera etapa de la Colonia (1496-1550). Estructura administrativa colonial, siglos XVI y XVII.

Fuente: Martín y Múscar (1992, pp. 99, 117). 
Finalmente, la metamorfosis física sufrida por los poblados precolombinos condujo a una transformación cultural indígena, al ser reem- plazados los templos sagrados por las iglesias cristianas, y las residenciales autóctonas por los cabildos y casonas europeas.

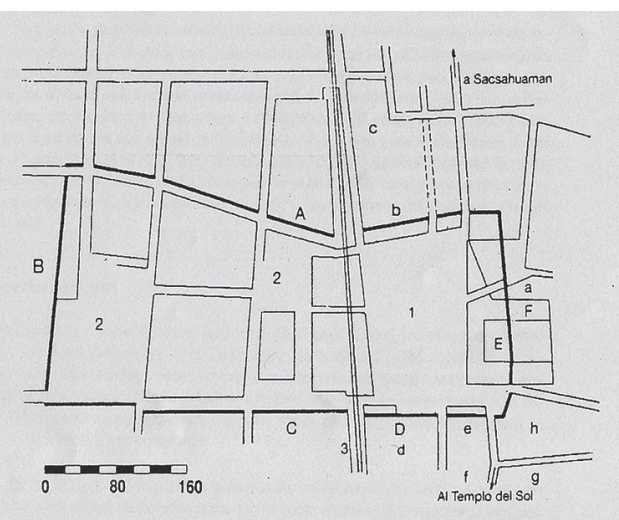

Plano de la Plaza de Cuzco incaico. Las líneas finas señalan el trazado del centro de la actual ciudad, originado en los primeros años de la colonia. Construcciones Incaicas: a- Palacio de Viracocha Inca, b- Palacio de Pachacuti, c- Escuela de los nobles, d- Palacio de Amarucancha, e- Palacio de Huascar, h- Hatum Cancha, 1- Aucaipata (Plaza de Armas), 2- Cusipata, 3- El cauce del Huatanay. Construcciones coloniales: A- El Cabildo, B- San Francisco, C- La Merced, D- La Universidad y la Campaña, E- La Catedral, F- La Sagrada Familia. Reconstrucción de Harth Terré E.

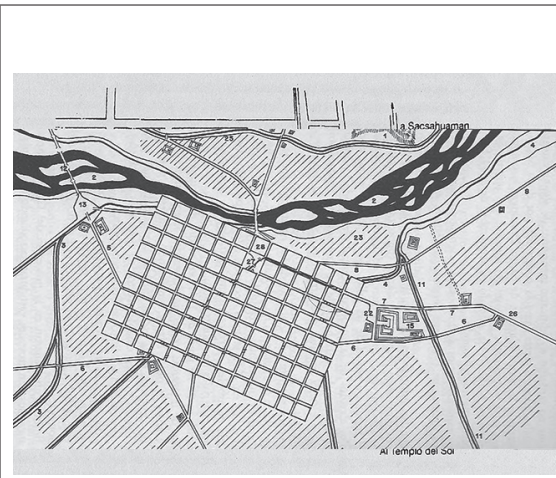

1535. La cuadrícula de Pizarro sobre Lima Prehispánica.

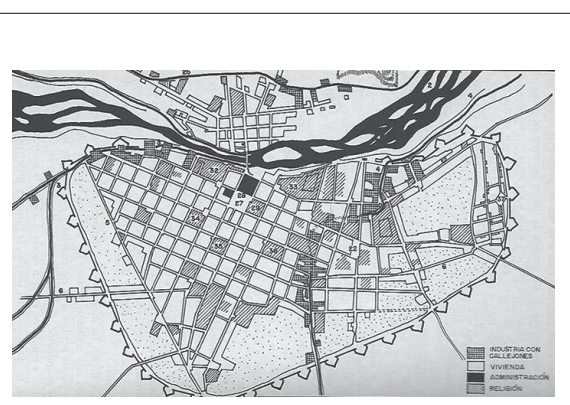

Lima colonial. Usos del suelo en la primera mitad del siglo XVIII.

Figura 3. Cuzco y Lima. Morfología urbana e imbricación de la ciudad precolombina y colonial.

Fuente: Hardoy (2009, pp. 385, 390), Múscar (1992, pp. 66, 132).

\section{La ciudad suramericana en el periodo republicano}

En cuanto a esta nueva etapa histórica, iniciada con los procesos "emancipatorios" desde la primera mitad del siglo xix, cabe consignar como factor sobresaliente la reproducción de las formas coloniales de uso del territorio bajo la nueva 
división de Estados Nacionales. A este tenor, los diferentes países "descolonizados" entraron en una fase de conflictos en torno al modelo de gobierno, la orientación económica y los nexos comerciales en esta nueva etapa “autonómica”, lo cual finalizó en un desplazamiento de la supremacía colonial ibérica a la dominación del librecambismo mercantilista inglés $\mathrm{y}$, posteriormente, norteamericano.

En medio de este complejo panorama social, económico y político de nueva dependencia (1830-1860), a nivel de la urbanización se intensifica la primacía y concentración de poderes en las ciudades capitales, de modo que no se producen cambios sustanciales con relación a las modalidades de la colonia. Hasta cierto punto, la diferencia con las formas precedentes se empieza a desencadenar con el aluvión de inmigrantes al área austral del continente en Argentina, Uruguay y sur de Brasil, a partir de 1870 y 1880 , cambiando la dinámica de urbanización que hasta ese momento se había adelantado con avances sincrónicos entre los diversos países de América de sur.

Sin duda, la recepción de estas diásporas le dieron un nuevo impulso a las ciudades portuarias, que, en los últimos tres decenios del siglo xix cobraron mayor importancia y se convirtieron en centros de atracción y arraigo; al mismo tiempo la agricultura, en diversas áreas rurales, también conglomera y cohesiona población, posibilitando un floresciente periodo fundacional de centros urbanos de carácter interior en territorios baldíos allende las zonas de explotación de herencia colonial. Así se origina un avance significativo en la ocupación de los espacios vacíos: sur de Chile, sur y norte de Argentina, las tierras paulistas, Paraná, Mato-Grosso, Río Grande do Sul en Brasil, etc.

Luego, entre 1900 y 1930, sobrevino la introducción al capitalismo comercial del resto de los países de América del Sur, replicando el modelo de relaciones comerciales inequitativas y permitiendo el acceso monopólico de los principales recursos naturales a los países desarrollados.

En esencia, esta etapa, señalada de manera certera por el economista Paul Singer como de "dependencia consentida" (cit. en: Faletto, 2007, p. 51), forjó la concentración de amplios beneficios económicos y políticos a los grupos dirigentes de 
la región, al permitir la intervención británica en las economías nacionales. A renglón seguido, se observa en la Tabla 3 la vinculación de los países del sur con los mercados europeos, concretándose desde el periodo finisecular un intercambio desigual entre los productos de exportación e importación, siendo las ciudades los espacios de acopio, distribución y comercialización de esta dinámica económica.

Tabla 3. Modo de articulación de Suramérica al periodo del capitalismo comercial, 1860-1930

\begin{tabular}{|c|c|c|}
\hline $\begin{array}{l}\text { Región y países } \\
\text { suramericanos }\end{array}$ & $\begin{array}{c}\text { Tipo de producción } \\
\text { - actividades } \\
\text { económicas }\end{array}$ & $\begin{array}{l}\text { Procesos y relaciones socio- } \\
\text { económicas en los sistemas urbanos }\end{array}$ \\
\hline Argentina, Uruguay & $\begin{array}{l}\text { Sector agropecuario } \\
\text { exportador }\end{array}$ & $\begin{array}{l}\text { Fusión de intereses entre la burguesía } \\
\text { comerciante platense y los propietarios } \\
\text { ganaderos del interior; experimentaron } \\
\text { un fuerte crecimiento económico } \\
\text { cuyo sector terciario se concentró casi } \\
\text { exclusivamente en las capitales, ya en } \\
\text { situación privilegiada al ser puertos de } \\
\text { exportación. }\end{array}$ \\
\hline Chile & $\begin{array}{l}\text { Auge productivo } \\
\text { centrado en la minería }\end{array}$ & $\begin{array}{l}\text { Relación entre el sector empresarial } \\
\text { minero extranjero y la naciente } \\
\text { burguesía nacional -como ejemplo se } \\
\text { produjo el desarrollo de las empresas } \\
\text { salitreras en Antofagasta y Tarapacá-. }\end{array}$ \\
\hline Brasil & $\begin{array}{l}\text { Sector agrícola } \\
\text { exportador, } \\
\text { posteriormente } \\
\text { complementado con la } \\
\text { minería }\end{array}$ & $\begin{array}{l}\text { Imbricación entre la burguesía } \\
\text { emergente y los capitales extranjeros } \\
\text { para el desarrollo de una nueva } \\
\text { agricultura de exportación (café), } \\
\text { además de la industrialización de la } \\
\text { minería en Minas Gerais, con epicentro } \\
\text { en Bello Horizonte. }\end{array}$ \\
\hline $\begin{array}{l}\text { Países del interior } \\
\text { de Suramérica y los } \\
\text { del norte del área } \\
\text { Andina: Bolivia, } \\
\text { Paraguay, Perú, } \\
\text { Ecuador, Colombia, } \\
\text { Venezuela }\end{array}$ & $\begin{array}{l}\text { Permanecieron casi } \\
\text { al margen de la nueva } \\
\text { estructura económica. } \\
\text { Vinculación tardía } \\
\text { a través de la } \\
\text { explotación agraria y } \\
\text { minera. }\end{array}$ & $\begin{array}{l}\text { Sus respectivas sociedades estuvieron } \\
\text { dominadas por la oligarquía } \\
\text { terrateniente, así su sistema urbano } \\
\text { estuvo reducido a la herencia de la } \\
\text { colonia española. }\end{array}$ \\
\hline
\end{tabular}

Fuente: Elaboración propia con base en Castells (1974, p. 74), Santos (1973, pp. 49-51). 


\section{La ciudad suramericana en la fase de modernización}

En este periodo, ante la ruptura de los mecanismos del mercado internacional y la limitación de las importaciones en el contexto de la crisis económica de 1929, se produjo un redireccionamiento del modelo productivo en los diferentes países de la región, al impulsar la expansión de la industria para dejar atrás la histórica dependencia del sector primario de la economía. Sin embargo, esta ilusión de autonomía no pasó, en palabras de Singer (cit. en Faletto, 2007, p. 52), de ser una nueva etapa de "dependencia tolerada”, en razón a que la impronta de desarrollo nacional a través de la industrialización continuó requiriendo la adquisición extranjera de bienes de capital, de equipos y tecnología, y de capital de inversión.

Además, aunque el Estado ejecutó intervenciones "modernizadoras" tanto en el ámbito urbano, con la industrialización, como en el rural, con la implementación de la "revolución verde”, los principales beneficiados de estas acciones continuaron siendo las élites nacionales; por consiguiente, el resultado de esta monopolización, en el caso de la agroindustrialización, fue la coalescencia entre el poder gamonal y los "nuevos empresarios agrarios", quienes usufructuaron las mejores tierras de cultivo, en detrimento de las formas tradicionales de producción campesina, lo que originó la pauperización de esta población y su diáspora masiva a las ciudades.

De esta forma, se puede afirmar que el crecimiento urbano durante esta fase tuvo como factores determinantes, más que la atracción de población ejercida por los puestos de empleo en las industrias, otros condicionantes de orden económico $^{8}$ y político $^{9}$ que precipitaron las migraciones rural-urbanas en una intensidad dramática. Un corolario espacial de estos procesos de desplazamiento de población campesina a la ciudad ha sido la localización de estos grupos en los

8 La descomposición de las estructuras rurales por la monopolización plutocrática produjo como efecto colateral un crecimiento inusitado de las ciudades en una proporción que superó la creación de empleo formal y la prestación institucional de servicios sociales básicos a la nueva población urbana. Por esta razón, se desencadenó una ampliación de las áreas de exclusión y tensión social constituidas por los inmigrantes rurales en situación de desempleo.

9 Como reflejo de los factores políticos, sobresale el caso de "La violencia" en Colombia, periodo avieso que causó fuertes procesos de desplazamientos rurales hacia las principales ciudades del país. Este fenómeno ha quedado constatado en el incremento de la población urbana (12,8 \% en 1938 a $40 \%$ en 1968). Citado con base en: Santos, M. 1973, p. 33 
inquilinatos y los empobrecidos arrabales periféricos.

Justamente, en representación de la "ciudad precaria y excluyente", se observa en la siguiente figura el caso del desarrollo marginal en Bogotá, fenómeno localizado tanto en el interior de la ciudad, en áreas constituidas por edificios vetustos del centro histórico, como en zonas

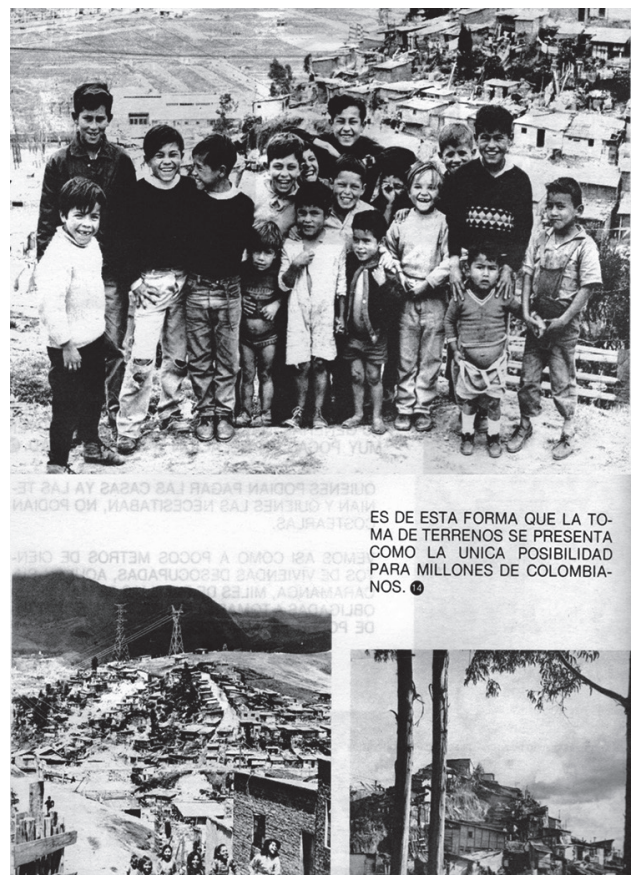

alejadas y mal comunicadas, donde se han extendido los denominados "barrios de invasión", áreas caracterizadas de manera inexacta desde la planificación urbana como "zonas subnormales", siendo estos, precisamente, "normales" a la producción de la ciudad no incluyente del modelo de desarrollo subordinado y dependiente que les dio origen.

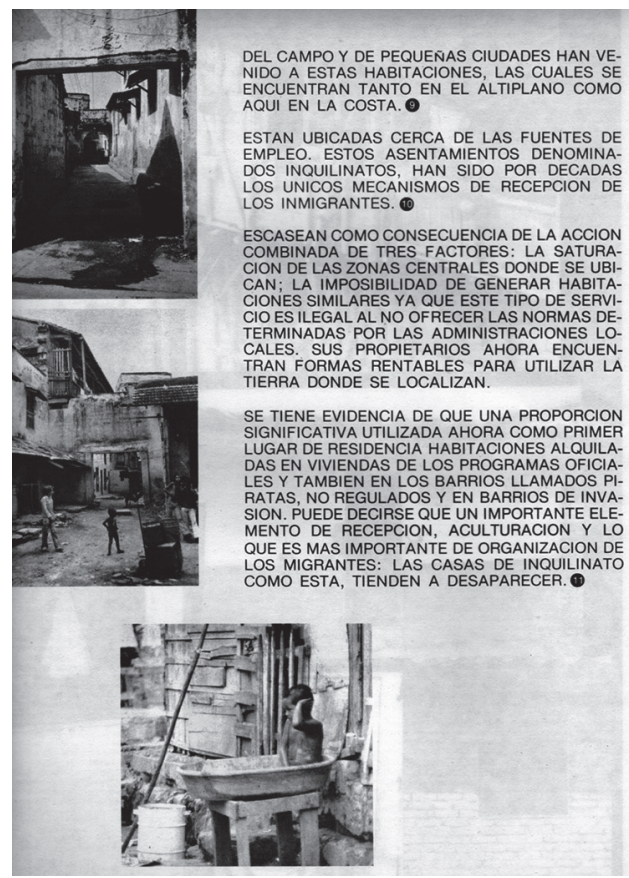

Figura 4. Bogotá. Configuración de la ciudad marginal en la década de los sesenta del siglo xx.

Fuente: Revista Escala, año 12, N. ${ }^{\circ} 83$. s.f.

En consecuencia, la naturaleza desigual de la ciudad del periodo de modernización configuró una espacialidad segregada, expuesta en la construcción de áreas "informales" con gran precariedad social y urbanística, cada vez más representativas en el conjunto urbano, 
$\mathrm{y}$, de otro lado, la consolidación de fragmentos de ciudad "formal", planificados bajo los preceptos del urbanismo racional funcionalista (zonning), con áreas industriales, sectores de servicios y zonas residenciales. Como resultado de estos procesos urbanos de inequidad, se formó una sectorización residencial por clases sociales, ejem- plificada en las extensas barriadas periféricas y las zonas de tugurios del centro para los grupos sociales de rentas bajas, junto a la localización concentrada en el extremo de la ciudad compacta de los grupos sociales de mayores ingresos, ante su traslado definitivo a nuevos barrios planificados de alto standing -cono de riqueza-.

Tabla 4. Patrón de segregación del periodo de modernización en Suramérica

\begin{tabular}{|l|l|}
\hline $\begin{array}{c}\text { Patrón de segregación durante } \\
\text { el periodo de modernización }\end{array}$ & Expresión gráfica \\
\hline $\begin{array}{l}\text { Se configuró un espacio urba- } \\
\text { no altamente diferenciado, con } \\
\text { barrios exclusivos para las cla- } \\
\text { ses medio-altas (cono o zona de } \\
\text { privilegio -verde oscuro-), zo- } \\
\text { nas residenciales planeadas para } \\
\text { la clase obrera (verde medio) y } \\
\text { áreas de autoconstrucción para } \\
\text { la población no incorporada a las } \\
\text { actividades económicas formales } \\
\text { (verde claro). }\end{array}$ \\
\hline
\end{tabular}

Fuente: Tomado de Sabatini y Cáceres (2005, p. 4).

Por demás, aunque la extensión del desarrollo urbano planificado no fue predominante en la morfología de las ciudades, comparado con el crecimiento informal, se destacan ciertas intervenciones, como los bulevares arbolados, los ejes de circulación jerarquizados, el trazado de supermanzanas, la construcción de unidades habitacionales y la ordenación de los barrios populares, entre otra clase de obras interesadas en lograr una imagen urbana equilibrada, mas no en atender los problemas sociales de los grupos menos favorecidos. 
Como evidencia de esta apertura inicial a una nueva forma de pensar la ciudad moderna en Suramérica, se reconoce que el mismo Le Corbusier diseñó los croquis de urbanismo para Bogotá, Río de Janeiro, Sao Paulo y Buenos Aires; a partir de estas ideas se elaborarían numerosos proyectos urbanos, la mayoría de los cuales no tendrían mayor trascendencia, y otros, como en el caso de Brasilia, llegarían con el tiempo a concretarse.
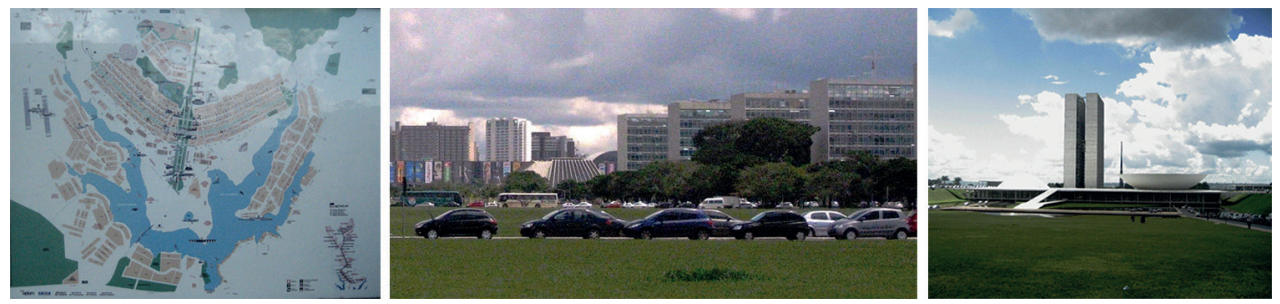

Figura 5. Brasilia. Monumentalidad y zonificación urbana. Áreas funcionales de carácter institucional, ejes de circulación vial jerarquizados, etc.

Fotos: Jorge Andrés Rivera.

Más tarde, desde las décadas de los setenta y los ochenta, se produce en el ámbito económico un nuevo ciclo de recesión que marca la crisis del proyecto de modernización nacional a través de la industrialización, vía sustitución de importaciones. Esta situación da lugar a un proceso de reorientación de la política económica, conocida como el "neoliberalismo", que centra su atención en la liberalización de las importaciones, la eliminación de las medidas proteccionistas y el fomento a la radicación de ca-

10 En 1956 se decidió trasladar la capital federativa brasileña de Río de Janeiro hacia el oeste con la fundación de Brasilia (capital nacional desde 1960). Citado con base en: Martín L., M. A.; Múscar B., E. 1992, p. 211. pitales multinacionales, aspectos que han tenido efectos visibles en la reconfiguración de las ciudades de Suramérica, como se expone a continuación.

\section{La ciudad suramericana en el periodo neoliberal}

En primer lugar, es menester indicar que el modelo neoliberal se caracteriza por la flexibilidad de intervención de los agentes privados en la prestación de los diferentes servicios y actividades requeridos por la población (empleo, seguridad social, vivienda, etc.). De otro lado, como lo enuncia el geógrafo David Harvey en su libro Breve 
historia del neoliberalismo, el rol del Estado se circunscribe a velar por los derechos de propiedad privada a partir de

crear y preservar el marco institucional apropiado para el desarrollo de estas prácticas. Por ejemplo, tiene que garantizar la calidad y la integridad del dinero. Igualmente, debe disponer las funciones y estructuras militares, defensivas, policiales y legales que son necesarias para asegurar los derechos de propiedad privada... (2009, p. 6).

En otras palabras, el Estado debe abandonar las políticas de intervención keynesianas y entregar a los grandes conglomerados multinacionales del sistema financiero, de servicios e industria el cumplimiento de sus funciones o competencias de provisión social y manejo de las áreas estratégicas de las economías nacionales.

Otro aspecto central en el origen del neoliberalismo en la región sudamericana fue la pesada carga de la deuda externa, situación que hizo que los bancos centrales de los países prestamistas -en particular los Estados Unidos- mantuvieran la exigencia de efectuar una mayor transferencia de los excedentes nacionales hacia los países acreedores, al igual que el pago de los intereses que habían sido diferidos mediante el otorgamiento de nuevos créditos. De esta manera, con el fin de responder a la incapacidad de pago del endeudamiento entre Estados, se traspasó esta deuda a la banca internacional. Sobre este aspecto, Faletto asevera que "la banca privada multinacional desplazó a los prestamos gobierno a gobierno, e incluso a los bancos intergubernamentales como el Banco Mundial, el Banco Interamericano, etc." (2007, p. 53).

Además de lo anterior, se impuso, como condición sine qua non $\mathrm{y}$ punto de partida para la renegociación de la deuda, asumir la doctrina económica neoliberal de desregulación, privatización e inversión extranjera; esto ha generado en la estructura territorial el reforzamiento de la histórica primacía y hegemonía de las capitales o de las principales ciudades en el contexto de la articulación económica nacional-internacional, como también, el consecuente desequilibrio urbano-regional en cada país. Dichas circunstancias se deben, entre otras razones, a que las compañías financieras trasnacionales efectúan la gestión e inversión del capital 
globalizado en aquellas ciudades donde se ha centralizado el poder a escala nacional y se han fortalecido sus vínculos con la economía mundial; a la par, estas cuentan con las infraestructuras adecuadas y la formación de capital humano competente para obtener los beneficios y tasas de retorno esperadas de las inversiones.

Por otra parte, sobre las repercusiones de la aplicación irrestricta de las medidas neoliberales en las ciudades del continente, se identifican, con diferentes grados de intensidad y presencia espacial, los fenómenos de gentrificación o aburguesamiento de los centros históricos, de las áreas rurales campesinas cercanas a la ciudad y de otras zonas expuestas a la especulación inmobiliaria y la rentabilidad financiera del negocio privado de la construcción; así mismo, la ocurrencia del proceso de metropolización e interconexión superlativa de las ciudades, y por último, en algunas urbes suramericanas, la renovación de las antiguas zonas francas, portuarias, industriales $\mathrm{y}$ manufactureras en crisis.

En este orden de ideas, los cambios urbanos están relacionados con la presión económica que produce la hipervaloración del suelo en sectores de la ciudad estratégicamente ubicados, por el interés manifiesto de inversiones futuras y la segura obtención de ganancias. Entre ellos sobresalen, primero, la desposesión territorial de la población de ingresos medio-bajos, que históricamente ha vivido en barrios del espacio intraurbano, al igual que de las comunidades campesinas que han habitado en los espacios rurales.

Sobre estas dinámicas de elitización, el arquitecto y urbanista Ernesto López-Morales (2013), en su texto sobre la Gentrificación en Chile, plantea nuevas perspectivas de análisis con base en una lectura crítica de los aspectos teóricos y empíricos de este fenómeno. Entre sus principales aportes formula que más allá de los cambios estéticos relacionados con la transformación física del espacio aburguesado, es insoslayable entender su carácter estructuralmente económico-político, ya que este es un problema de extracción y distribución desigual, tanto de la ganancia obtenida por el uso del suelo, como del acceso a los bienes públicos urbanos; todo ello posibilitado y, a veces, conducido por el Estado. 
Al mismo tiempo, en el espacio metropolitano se viene presentando con intensidad la gentrificación rururbana, dinámica territorial que está relacionada con la conversión a valor de cambio de atributos naturales y sociales, tales como las funciones ecosistémicas del entorno y la calidad ambiental, junto a la belleza escénica del paisaje rural, la experiencia directa con el imaginario campestre y la idealización bucólica del espacio campesino. En efecto, este fenómeno se ha incrementado desde la década de los noventa gracias al desarrollo de los megaemprendimientos inmobiliarios (denominados "clubes de campo, barrios cerrados, ciudades-pueblo, miniciudades", etc.), siendo en general un proceso "no planificado y de alta complejidad", tal y como lo han definido diferentes investigadores del crecimiento de las metrópolis del continente (Janoscka, 2002; De Mattos, 2004; Prévôt-Schapira, 2002; Ciccolella, 2004, entre otros).

Además, en algunas ciudades, como Bogotá ${ }^{11}$, Santiago de Chile ${ }^{12}$

11 En Bogotá, nace el Centro Creativo Textura como una iniciativa de reciclar una antigua fábrica textil para dar paso a talleres para artistas y salas de exposición. Citado en: http://www.centrocreativotextura.com/quees/\#

12 El centro cultural Matucana 100 ocupa las dependencias de las antiguas bodegas de la Dirección de Aprovisionamiento del Estado. Este espacio cuenta y Buenos Aires ${ }^{13}$, se viene adelantando la conversión de los antiguos puertos, polígonos industriales y talleres de manufacturas del periodo de impulso "modernizador" -que han quedado abandonados como testimonio del fin de las políticas keynesianas de apoyo a la industria nacional-, a áreas de servicios culturales y de ocio (museos, galerías de arte, librerías, restaurantes, etc.), al igual que a viviendas exclusivas tipo loft o a empresas de Innovación y Desarrollo ( $+\mathrm{D}$, tecnologías de la información, las telecomunicaciones y el diseño de vanguardia).

Este tipo de intervenciones de renovación urbana ponen en evidencia, por un lado, la estandarización y banalización arquitectónica, tras la repetición de los estilos y diseños en las construcciones, y, de otro, el papel fundamental que tiene la planificación urbana posmoderna, que "no piensa la ciudad en su totalidad", sino que favorece el trabajo fragmentario de actuaciones puntuales. De este modo, se

con salas de teatro y galería de artes visuales. Véase: http://www.m100.cl/

13 El proyecto Puerto Madero S.A. implicó la recuperación de 170 hectáreas, transformando este espacio en un exclusivo centro residencial, gastronómico y de negocios de la ciudad de Buenos Aires. Citado en: http://www.puertomadero.com/ 
propugna idealmente la producción de un espacio urbano contemporáneo, futurista, con la participación de empresas internacionales en su gestión inmobiliaria, mercadeo $\mathrm{y}$ construcción (Figura 9).

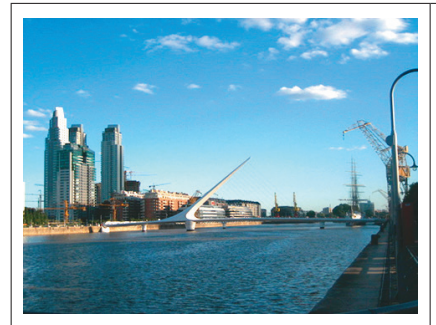

Renovación antiguo Puerto Madero, Yuppie-ficación. Buenos Aires, Argentina.

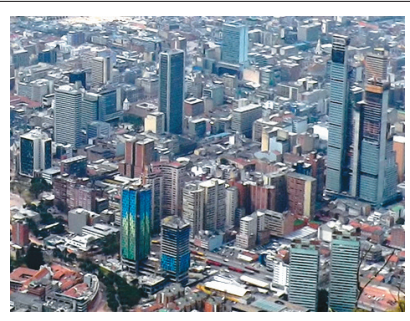

Proyecto Hotel Bacatá. Urbanalización arquitectónica Bogotá, Colombia.

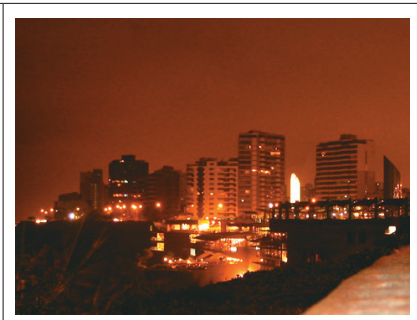

Lima, Perú. Agentes privados: Centro comercial Larcomar, Miraflores.

Figura 6. La ciudad neoliberal. Renovación urbana y ur-banalización.

Fotos: Jorge Andrés Rivera.

En este sentido, al abordar una de las características fundamentales del modelo de la ciudad neoliberal, como es la relación entre el papel del mercado y la configuración urbana, se observa que, ante la monopolización de la oferta residencial por los agentes privados (sistema financiero, promotores, empresas inmobiliarias y constructoras), tanto para los sectores de la población de mayores ingresos -en las áreas o cono de privilegio de la ciudad compacta y en las zonas rururbanas gentrificadas-, como para las clases sociales de bajos recursos económicos -en las periferias urbanas de esfuerzo popular y los bordes de desarrollo espontáneo e informal-, se ha constituido una morfología urbana dual o "híbrida", con un crecimiento interno o centrípeto (recentralización de la élite, junto a la densificación de los barrios tradicionales), y un desarrollo urbanístico disperso, difuso o centrífugo (avance de los guetos pobres al espacio metropolitano, más los condominios neo-rurales o segundas residencias rururbanas de confort $\left.^{14}\right)$.

14 La dispersión de las élites fuera de las áreas tradicionales de concentración es un cambio que se deriva de la concentración del capital y la aparición de los grandes proyectos inmobiliarios en el marco de la liberalización de los mercados del suelo. Hay ciudades más avanzadas en este proceso y otras que casi no lo muestran aún, pero es posible identificar esta tendencia general en la ciudad latinoamericana. También, los propietarios de terrenos periféricos han asumido que sus propiedades ya no están indefectiblemente destinadas a alojar actividades con baja capacidad de pago por el suelo, como la vivienda popular, sino que pueden acoger barrios cerrados, shoppings, grandes 
Sobre este aspecto, el economista Pedro Abramo propone una nueva categoría explicativa del fenómeno urbano latinoamericano, la ciudad "com-fusa":

el funcionamiento del mercado del suelo en las grandes ciudades latinoamericanas promueve, de forma simultánea, una estructura de ciudad compacta y difusa. Ello apunta a que las urbes latinoamericanas tienen una estructura generada por un uso del suelo que se compacta y se difunde, o se difunde y se compacta. En este sentido, la producción de la estructura urbana en América Latina concilia las formas compacta y difusa de uso del suelo y, de esta forma, promueve una forma particular: la ciudad "com-fusa" (2012, p. 36).

Dicho de otro modo, la máxima flexibilidad para la actuación privada ha traído grandes impactos como la mayor desigualdad socioespacial urbana. Primero, el mercado formal dirige su oferta a la reducida proporción de población de altos

supermercados, parques, oficinas u otros proyectos "modernos", como los que se observan dispersarse por la periferia de las ciudades latinoamericanas (Citado con base en: Janoscka, 2012). ingresos, siendo las respuestas del sector inmobiliario para este segmento social cada vez más sofisticadas, con urbanizaciones de altos estándares arquitectónicos, dotadas de seguridad privada, cerramientos, centros comerciales, etc. Segundo, los sectores medio-bajos de la población adquieren también sus viviendas en el mercado formal, aunque condicionados por las opciones existentes; así, el resultado de la acción privada para estos estratos lleva a la conformación de tejidos urbanos caracterizados por la alta densidad y las reducidas dimensiones de las viviendas, patrón que se repite tanto en los centros como en los barrios residenciales y edificios de interés social periféricos.

En tercer lugar, los grupos sociales excluidos y pauperizados han construido, al margen del mercado formal, una proporción significativa de las ciudades; es decir, que los sectores más pobres de la sociedad, tanto de manera individual como colectiva, y perfectamente organizada, han efectuado las invasiones, las parcelaciones clandestinas y la autoconstrucción de viviendas y de los servicios domiciliarios urbanos. 


\section{Conclusiones}

Después de este amplio recorrido geohistórico por el proceso de urbanización en América del Sur, se destaca, en primer término, el carácter centrípeto e interior del modelo de ocupación espacial y de poblamiento precolombino, expresión de sistemas geopolíticos centralizados y jerarquizados, constituidos por una organización social y territorial colectivista e integradora. Por el contrario, el período colonial subsiguiente se caracterizó por una ocupación litoral, periférica y desintegradora de la territorialización indígena precedente, configurando un patrón de poblamiento centrífugo que generó desbalance y descompensación entre las dinámicas franjas de actividad perimetrales y los amplios espacios interiores vacíos.

Este cambio en el uso del espacio geográfico se explica, entonces, por la naturaleza expoliadora $\mathrm{y}$ extractivista que sustentó ideológica y económicamente la intervención ibérica en Suramérica, al tener como gran propósito cubrir sus necesidades, ajenas a las de la población raizal, y entender el territorio como proveedor o productor de materias primas. Así, el pro- ceso milenario precolombino fue abruptamente transgredido por el pensamiento europeo de privatización, expoliación y dominación del espacio geográfico y la vida social que lo había integrado.

En efecto, proporcional al grado de avidez económica ibérica, se desarrolló el proceso de reducción de pueblos y asentamientos originarios, además de un ímpetu fundacional que constituyó en tan solo la primera mitad del siglo XVI una nueva configuración territorial americana. En este contexto histórico, los núcleos urbanos actuaron como motor del desarrollo de sus respectivas áreas de influencia, por lo que los espacios organizados a su alrededor estuvieron sujetos a los avatares de su evolución. De hecho, durante la época colonial los espacios regionales fueron activados conforme se abrían las posibilidades de explotación de los recursos naturales encontrados, circunstancia que dio lugar a la generación de ciclos económicos característicos (azucarero, aurífero, entre otros) que demandaban organizaciones territoriales propias.

Entre tanto, en las postrimerías decimonónicas se presenta el surgimiento de un eje de crecimiento 
alternativo que suplantó las antiguas zonas de dominación colonial instaladas en los andenes costeros. Justamente, la apertura del mundo agrícola y ganadero potenció espacios que habían permanecido marginales o poco afectados por el desarrollo económico. En otras palabras, durante el siglo XIX ocurre la fundación de diversos centros urbanos de carácter interior, principalmente en el Cono Sur. Esta "conquista" de territorios continentales allende de la localización literal del período colonial, está relacionada con los proyectos económicos manejados por las élites nacionales para ampliar la frontera agrícola; para ello se estimula y favorece la inmigración europea.

Más tarde, dos hechos desencadenantes ocurren simultáneamente: la depresión económica de 1929 y la necesidad de adaptación a las circunstancias de la crisis a través de nuevas medidas y estrategias, como la determinación de dar comienzo a la industrialización vía sustitución de los productos que mayoritariamente eran importados por los países de la región. Sin embargo, tras la falta de inversión estatal, aunado al aumento de la deuda externa, el modelo de desarrollo nacional "autónomo" y moderno empezó a decaer a partir de los setenta, lo que derivo, entre otros aspectos, en las fuertes migraciones de la época y en la conversión de algunas zonas urbanas en áreas-refugio de la pobreza. Así, la morfología urbana exhibió en los bordes y periferias de las ciudades los espacios de lucha y esfuerzo popular por la vivienda y el hábitat digno, mientras que las élites se consolidaban a nivel residencial en una zona compacta de gran calidad arquitectónica y urbanística -cono de riqueza-.

Finalmente, con el devenir de los años noventa, la universalización del neoliberalismo ha hecho que el modelo de gestión y desarrollo urbano cambie sus objetivos $y$, por tanto, sus estrategias y formas de actuación y la espacialidad de estas. Es así como el interés de la ciudades del subcontinente por ser visibles en el contexto global las ha llevado a olvidar sus responsabilidades sociales con el conjunto de la ciudadanía, y, por otro lado, han pasado de actuaciones de urbanismo a escala de ciudad -liderados por el Estado como agente urbano- a proyectos inmobiliarios icónicos relacionados con el establecimiento de edificios y zonas urbanas para centros de negocios corporativos, firmas internacio- 
nales del comercio, cadenas hoteleras, etc. - con intervención principal del mercado-.

De esta forma, se hace evidente el tránsito del paradigma funcional racionalista del periodo de modernización -con sus instrumentos técnico-políticos, como la zonificación y el Plan Regulador- al urbanismo empresarial, inspirado en la planificación flexible, la identificación de oportunidades de negocio en el tratamiento de áreas "promisorias" de la ciudad y la asimilación del modo de funcionamiento privado por parte del sector públi- co. Dicho de otro modo, en palabras del destacado geógrafo David Harvey: "el objetivo es generar en el proceso de urbanización una sinergia suficiente para que tanto los intereses privados como los estatales puedan crear igualmente las rentas monopolistas" (2005, p. 46).

\section{Dedicatoria}

Este escrito, producto de un proceso de reflexión sobre la realidad territorial de Suramérica, está dedicado a la memoria de Ana María Patiño, mi abuela.

\section{Referencias}

Abramo, P. (2012). La ciudad com-fusa: mercado y producción de la estructura urbana en las grandes metrópolis latinoamericanas. Revista Eure, 38(114), 35-69.

Abreu, A. M. (2013). A Evoluçao Urbana do Rio de Janeiro. $4^{\text {a }}$ ed. Rio de Janeiro: Instituto Pereira Passos.

Capel, H. (2002). La morfología de las ciudades. I. Sociedad, cultura y paisaje urbano. Barcelona: Ediciones Serbal, Colección "La Estrella Polar" -37.

Castells M. (1974). La cuestión urbana. Madrid: Siglo XXI.

Ciccolella, P. (2004). Metrópolis en transición: Buenos Aires al desnudo entre la expansión económica y la crisis. En: Aguilar A. (coord.). Procesos metropolitanos y grandes ciudades. Dinámicas recientes en México y otros países, (pp. 53-77). México: Universidad Nacional Autónoma de México.

Cunill G, P. (1981). La América Andina. Editorial Ariel.

De Mattos, C. (2004). Santiago de Chile de cara a la globalización ¿otra ciudad? En: Aguilar, A. (Coord.). Procesos metropolitanos y grandes ciudades. Dinámicas recientes en México y otros países, (pp. 19-52). México: Universidad Nacional Autónoma de México. 
Faletto, E. (2007). Dimensiones sociales, politicas y culturales del Desarrollo: Antología. Santiago de Chile: Catalonia.

Fridman, F. \& Natal F. S. (s.f.). Cidade Flutuante: Os portos do Rio de Janeiro Colonial. IV Seminario de Historia da Cidade e do Urbanismo.

Hardoy, J. E. (1996). La ciudad y el territorio: 1. El proceso de urbanización. En: Segre. R. América Latina en su arquitectura. (pp. 38-62). Octava edición. México: Siglo XXI editores S.A.

Hardoy, J. E. (2009). Ciudades precolombinas. Buenos Aires: Infinito.

Harvey, D. \& Smith N. (2005). Capital financiero, propiedad inmobiliaria y cultura. Barcelona: Bellaterra (Cerdanyola del Vallès): Museu d'Art Contemporani de Barcelona; Servei de Publicacions de la Universitat Autònoma de Barcelona.

Harvey, D. (2009). Breve historia del neoliberalismo. Segunda edición. Madrid: Akal.

Hiernaux, D. y Lindon, A. (Dirs.). (2006). Tratado de Geografía Humana. Universidad Autónoma Metropolitana de Iztapalapa: Anthropos.

Janoschka, M. (2002). El nuevo modelo de la ciudad latinoamericana: fragmentación y privatización. Eure, 28(85), 11-30. Santiago de Chile: Estudios Urbano Regionales.

Lois, G. C. R. (coord.), (2012). Los espacios urbanos. El estudio geográfico de la ciudad y la urbanización. Madrid: Biblioteca Nueva.

López-Morales, E. (2013). Gentrificación en Chile: Aportes conceptuales y evidencias para una discusión necesaria. Revista de Geografia Norte Grande, 56, 31-52.

Martín L. M. A. y Múscar B. E. (1992). Proceso de urbanización en América del Sur. Modelo de ocupación del espacio. Madrid: Mapfre.

Montoya, J. W. (2006). Cambio urbano y evolución discursiva en el análisis de la ciudad Latinoamericana: De la dependencia a la globalización. Bogotá: Universidad Nacional de Colombia. Facultad de Ciencias Humanas. Departamento de Geografía. Serie Trabajos en Geografía.

Parsons, J. (1979). La Colonización Antioqueña en el Occidente Colombiano. Carlos Valencia Editores.

Prévôt-Schapira, M. F. (2000). Segregación, fragmentación, secesión. Hacia una nueva geografía social en la aglomeración de Buenos Aires. Economía, Sociedad y Territorio, 2(7), 405-431.

Sabatini, F. y Cáceres, G. (2003). Relación entre promoción inmobiliaria y la segregación residencial. Giros insospechados de la ciudad latinoamericana. Santiago de Chile. 
Santos, M. (1973). Geografía y economía urbanas en los países subdesarrollados. Vilassar de Mar, Barcelona: Oikos-tau.

Santos, P., J. M. (1992). El desarrollo de la geografía urbana en la evolución del pensamiento geográfico contemporáneo. Espacio, Tiempo y Forma. Serie VI, Geografía, t. V, p. 9-40.

Segre. R. (1996). América Latina en su arquitectura (pp. 3-37). Octava edición. México: Siglo XXI.

Revista Escala (s.f.). La lucha por un techo. Enseñanza de los asentamientos espontáneos de vivienda. Revista Mensual Bolivariana de Arquitectura, Arte e Ingeniería, 12(83). 
Recepción: 21 de enero de 2016

Evaluación: 22 de febrero de 2016

Aprobación: 19 de abril de 2016 